\title{
Treatment and prophylaxis strategies for deep vein thrombosis during COVID-19 outbreak
}

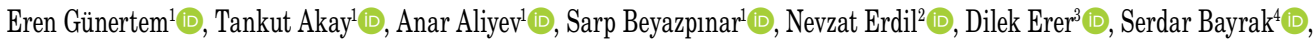 \\ Tanzer Çalkavur ${ }^{5}$ (D) Kürşat Bozkurt ${ }^{6}$ (D) \\ ${ }^{1}$ Department of Cardiovascular Surgery, Başkent University Medical Faculty, Ankara, Turkey \\ ${ }^{2}$ Department of Cardiovascular Surgery, Inonu University Medical Faculty, Malatya, Turkey \\ ${ }^{3}$ Department of Cardiovascular Surgery, Gazi University Medical Faculty, Ankara, Turkey \\ ${ }^{4}$ Department of Cardiovascular Surgery, Dokuz Eylül University Medical Faculty, Izmir, Turkey \\ ${ }^{5}$ Department of Cardiovascular Surgery, Ege University Medical Faculty, Izmir, Turkey \\ ${ }^{6}$ Department of Cardiovascular Surgery, Istanbul University Cerrahpaşa Medical Faculty, Istanbul, Turkey
}

\begin{abstract}
Since the first case of coronavirus disease 2019 (COVID-19) was reported at the end of 2019, this outbreak has spread to more than a million people around the world and become a pandemic. The group most affected by the outbreak with the highest mortality rate is elderly people with known vascular diseases or a high risk of developing vascular pathologies. It is evident that in this group of patients, there is a high risk of deep vein thrombosis (DVT) occurrence. In this current extraordinary era, management will be more challenging. In this article, we aimed to prepare a recommendation guide including the thromboprophylaxis and management of patients diagnosed with DVT during the COVID-19 outbreak.
\end{abstract}

Keywords: COVID-19, deep vein thrombosis, pandemic, prophylaxis, treatment.

A novel coronavirus was identified as the cause of pneumonia cases in Wuhan, a city in the Hubei province of China, which rapidly spread throughout China. ${ }^{[1]}$ Followed by a growing number of cases all around the world, particularly in Europe, the outbreak has been defined a pandemic by the World Health Organization (WHO).

The causative virus, formerly called "2019 novel coronavirus" (2019-nCoV), was termed "severe acute respiratory syndrome-coronavirus-2" (SARS-CoV-2) and the disease it causes was named "coronavirus disease 2019 (COVID-19)". ${ }^{[2,3]}$

Since the first case of COVID-19 was officially confirmed in Turkey on March 11, 2020, the number of cases exceeded 40,000 and more than 500 deaths have been reported.

Our knowledge about the course of the disease is increasing each day. Although the findings related to this new clinical threat generally belong to the respiratory system, the group most affected by the outbreak with the highest mortality rate are elderly people with known vascular diseases or with a high risk of developing vascular pathologies during their treatment.

In this group, intensive care unit hospitalization rates are quite high. It is evident that in these immobile patients with advanced age $(<70)$, there is a high risk of developing deep vein thrombosis (DVT). 
If a COVID-19 patient, who is already undergoing severe respiratory involvement, complicates with DVT and pulmonary venous thromboembolism (VTE), the clinical situation will worsen, the treatment periods will be prolonged and become more challenging.

In order to prevent the spread of the disease, individuals are being requested to "stay at home" in our country like in the whole world. A majority of people started self-isolations at home and try to work remotely using laptops/smart phones. Therefore, it would not be wrong to say that social isolation strategies will likely reduce individuals' physical activity, and lead to decreased mobility. As it is known, immobility is a significant risk factor for DVT development. Considering this, we can predict that the incidence of DVT may increase during the pandemic.

In this study, we aimed to prepare a recommendation guide under different topics in light of the current literature regarding DVT prophylaxis and treatment approaches for the uninfected population, follow-up of patients diagnosed with DVT during the COVID-19 outbreak as well as the preferences in interventional or medical treatments.

\section{PREVENTION FROM DEEP VEIN THROMBOSIS FOR UNINFECTED PEOPLE}

In order to prevent the spread of the COVID-19 and not be affected by this disease, it is recommended by the authorities that people around the world isolate themselves at home. People are encouraged to work at home on a "home-office" basis. This situation causes a more sedentary life style. As it is known, immobility is an important risk factor for DVT. Therefore, it is possible to say that the incidence of DVT in the population will increase during the pandemic. Taking some measures is crucial for people in the risk group (Table 1). ${ }^{[4]}$

Recommendation 1: Measures to be taken by individuals staying at home: If possible, avoid being immobile for long periods at home. Individuals working from home should avoid sitting for long hours and do several exercises for working the calf muscle while sitting on the chair (i.e. while your feet are on the ground, lift the heels up and take the fingertip position). It is recommended to stand up and walk for a while. Attention should be paid to intake fluids sufficiently. People should not delay applying to a healthcare institution in case of occurrence of any symptoms that may be related to DVT.

\section{MANAGEMENT OF UNINFECTED INDIVIDUALS UNDER FOLLOW-UP WITH DEEP VEIN THROMBOSIS}

Lifetime incidence of deep vein thrombosis is between $2.5 \%$ and $5 \% .{ }^{[5]}$ In the population, there is a considerable number of patients under anticoagulant therapy due to DVT. It is important to develop specific treatment and follow-up algorithms for such patients. We should prefer approaches that will keep these individuals away from health institutions unless it is necessary.

Recommendation 2: In order to prevent patients from applying to health institutions for international normalized rate control during the outbreak, physicians should consider switching anticoagulant therapy to low molecular weight heparin (LMWH) or direct oral anticoagulants (DOACs). Routine controls may be postponed to a date after the outbreak except for patients in Table 2 .

\section{MANAGEMENT OF PATIENTS WITH ACUTE DEEP VEIN THROMBOSIS DURING THE OUTBREAK PERIOD}

Incidence of VTE is around $104-183$ per 100,000 people/year. ${ }^{[6]}$ This can increase to $68 / 1,000$ in highrisk cases. ${ }^{[7]}$ Thus, it is observed that the frequency of VTE has increased in recent years. This means that during the outbreak, we are more likely to encounter outpatients who are diagnosed with acute DVT every day in healthcare facilities. In this group of patients, we should be sensitive to perform the most appropriate approach under the conditions of the current pandemic.

Although there has been no difference in the acute distal DVT patients in recent studies, reduced risk or severity of post-thrombotic syndrome has been demonstrated with catheter-directed treatment options in acute proximal (iliofemoral) DVT patients during follow-ups. ${ }^{[8-10]}$ For this reason, there is an

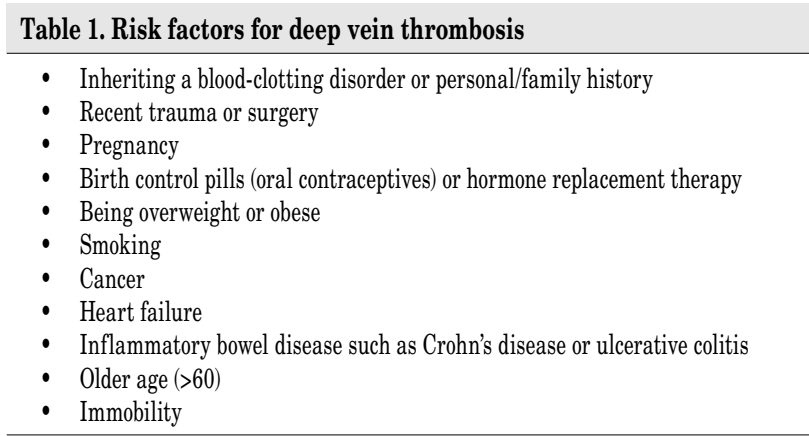


Table 2. Conditions requiring outpatients to apply to health institutions

- Major bleeding related with anticoagulant therapy (gastrointestinal bleeding, sudden neurologic disorders which can be related with central nervous system bleeding, etc.)

- Pulmonary thromboembolism-related symptoms (shortening of breath, sudden chest or back pain, etc.)

- Infectious findings in patients with venous ulcer (purulent discharge, local tenderness, redness, and warmth in ulcer area)

- Development of symptoms that may be associated with acute deep vein thrombosis in a different limb or diseased limb despite regular anticoagulant usage (hospitalization for an interventional treatment option can be considered in this situation)

increased tendency to adopt these treatment methods in daily practice. However, for interventional treatment methods, patients must be hospitalized for three to five days.

During the outbreak, this can be considered as unnecessary hospital bed occupancy; however, it also places patients under the risk of COVID-19. Moreover, according to the results of the Catheter Versus Anticoagulation study announced in early 2020, interventional treatments did not yield superior results compared to standard treatment. ${ }^{[11]}$ In light of these findings, we may assume that no consensus has been established on this issue yet and the discussions will continue for a while. Then, it would be appropriate to prefer standard anticoagulant treatment instead of interventional treatment methods particularly for individuals with COVID-19 risk factors during this period.

Another important issue that challenges physicians is deciding on the patients to be hospitalized. As highlighted in the Peripheral Artery and Venous Diseases National Treatment Guide published in $2016,{ }^{[12]}$ treatment at home is recommended as much as possible for patients with acute DVT. Again, in this guideline, it was emphasized that the patients mentioned in Table 3 should be treated in hospital:

Considering that the vast majority of patients cited in Table 3 is also at high risk for COVID-19, we believe that the decision should be established by the physician.

While conducting acute DVT treatment for in- or outpatients, LMWHs or DOACs may be a rational choice for the reasons we mentioned earlier in this paper.

Recommendation 3: Outpatients diagnosed with acute DVT during the outbreak should be
Table 3. Hospitalization indications for patients with acute deep vein thrombosis

- Patients with massive thrombosis

- Patients at high risk of bleeding

- Patients with active bleeding

- Recent surgery history

- Active peptic ulcer

- Advanced liver disease (international normalized rate >1.3)

- Thrombocytopenia $(<100,000)$ or familial bleeding disease

- Patients weighing less than $45 \mathrm{~kg}$ and more than $100 \mathrm{~kg}$

- Children

- Pregnant females

- Patients with other medical problems (dialysis requirement, etc.)

- Venous gangrene

treated at home if possible in first place. Preference of hospitalization should be left to the physician, according to comorbidities and COVID-19 risk factors of patient. Low molecular weight heparins or DOACs may be the first choice for anticoagulant therapy.

\section{DEEP VEIN THROMBOSIS TREATMENT AND PROPHYLAXIS IN HOSPITALIZED PATIENTS WITH COVID-19}

Hospitalized patients diagnosed with COVID-19 have a higher risk of developing DVT. Critically ill patients fulfill two criteria of Virchow's triad. First of all, they have reduced venous flow due to immobility. Moreover, immune reactions, which can trigger prothrombotic changes and endothelial damage, are likely according to recently reported investigations about COVID-19. ${ }^{[13]}$ In case of suddenonset hypoxia, respiratory distress or hypotension, VTE should be considered. Development of VTE may affect prognosis of COVID-19 patients with severe respiratory failure negatively. For this reason, it is crucial to conduct a risk analysis for DVT and start thromboprophylaxis as soon as possible in hospitalized patients with COVID-19. Management will be more challenging in case of DVT occurrence in hospitalized patients with COVID-19. In patients with low risk for bleeding, such as in those aged less than 65 years, and with absence of cancer history and recent trauma or surgery, pharmacomechanical catheter-directed thrombolysis may be appropriate. ${ }^{[14]}$ A case series conducted by Matusov et al..$^{[15]}$ demonstrated that in a population of critically ill patients, the bedside placement of the inferior vena cava filter is feasible and safe. This option should also be kept in mind by physicians for preventing VTE. In brief, each patient should be evaluated individually by the vascular team. 


\begin{tabular}{|l|l|l|l|l|l|l|l|}
\hline Drugs & Hydroxychloroquine & Azithromycin & Lopinavir/Ritonavir & Favipiravir & Remdesivir & Oseltamivir & Ribavirine \\
\hline Heparin & & & & & & & \\
\hline Enoxaparin & & & & & & \\
\hline Apixaban & & & & & \\
\hline Rivaroxaban & & & & & & \\
\hline Edoxaban & & & & & \\
\hline Dabigatran & & & & & \\
\hline Warfarin & & No interaction & Low risk & High risk \\
Do not use together & & \\
\hline
\end{tabular}

Figure 1. Drug interactions.

Recommendation 4: The risk of DVT should be assessed in all COVID-19 patients. Thromboprophylaxis should be given to all high-risk patients according to the National Institute for Health and Care Excellence guideline: ${ }^{[16]}$

- For creatinine clearance $(\mathrm{CrCl})>30$ : Give LMWH.

- For $\mathrm{CrCl}<30$ or acute kidney injury: Give dose-reduced LMWH of unfractionated heparin 500 units subcutaneously.

- All immobilized patients would benefit from intermittent pneumatic compression.

- Mechanical thromboprophylaxis should be used alone if platelets $<30,000$ or in the presence of any bleeding.

Recommendation 5: Consider VTE in patients with sudden-onset oxygen desaturation, respiratory distress or hypotension.

\section{MANAGEMENT OF COAGULOPATHY ASSOCIATED WITH COVID-19}

It has already been recognized that acute inflammatory response triggers activation of fibrinolysis. In a multicenter study including 191 COVID-19 patients, $3 \mathrm{sec}$ prolongation of prothrombin time or $5 \mathrm{sec}$ extension of activated partial thromboplastin time was present in $50 \%$ of the non-survivors and $7 \%$ of the survivors. Moreover, lower platelet counts were noted in $20 \%$ of the nonsurvivors and $1 \%$ of the survivors. ${ }^{[17]}$ For this reason, physicians should be careful while starting any anticoagulant therapy in the presence of DVT.

Recommendation 6: While starting an anticoagulant therapy, basic hemostatic system tests should have been screened. Bleeding risk analysis can be performed.

Recommendation 7: Abnormal coagulation test results do not require correction in patients without evident bleeding.

\section{ANTICOAGULANT DRUG INTERACTIONS IN COVID-19 PATIENTS}

Scientists are endeavoring to find specific drug options to control the virus. Several drugs such as chloroquine, arbidol, remdesivir, and favipiravir are currently undergoing clinical studies to test their efficacy and safety in the treatment of COVID-19 and some promising results have been achieved thus far. ${ }^{[18-21]}$ When an anticoagulant treatment is needed, physicians should be aware of the drug interactions below (Figure 1). ${ }^{[22]}$

Recommendation 8: While starting an anticoagulant therapy, potential drug interactions should be taken into account.

In conclusion, according to the current knowledge, we, as vascular surgeons, should develop certain algorithms for preventing DVT and identify possible treatment approaches to follow. While managing the treatment process, we should also protect the society and ourselves.

\section{Declaration of conflicting interests}

The authors declared no conflicts of interest with respect to the authorship and/or publication of this article.

\section{Funding}

The authors received no financial support for the research and/or authorship of this article. 


\section{REFERENCES}

1. Wang D, Hu B, Hu C, Zhu F, Liu X, Zhang J, et al. Clinical Characteristics of 138 Hospitalized Patients With 2019 Novel Coronavirus-Infected Pneumonia in Wuhan, China. JAMA. 2020 Feb 7. [Epub ahead of print]

2. Zhou P, Yang XL, Wang XG, Hu B, Zhang L, Zhang $\mathrm{W}$, et al. A pneumonia outbreak associated with a new coronavirus of probable bat origin. Nature 2020;579:270-3.

3. Naming the coronavirus disease (COVID-19) and the virus that causes it [Internet]. [cited 2020 Mar 21]. Available at: https://www.who.int/emergencies/diseases/ novel-coronavirus-2019/technical-guidance/namingthe-coronavirus-disease-(covid-2019)-and-the-virusthatcauses-it. [Accessed: Mar 23, 2020].

4. Anderson FA Jr, Spencer FA. Risk factors for venous thromboembolism. Circulation 2003;107:19-16.

5. White RH. The epidemiology of venous thromboembolism. Circulation 2003;107:I4-8.

6. Heit JA, Spencer FA, White RH. The epidemiology of venous thromboembolism. J Thromb Thrombolysis 2016;41:3-14.

7. Demir AM, Ümit EG. Kanserle ilişkili tromboz. Turkiye Klinikleri J Hematol-Special Topics 2015;8:66-74.

8. Enden T, Haig Y, Kløw NE, Slagsvold CE, Sandvik L, Ghanima W, et al. Long-term outcome after additional catheter-directed thrombolysis versus standard treatment for acute iliofemoral deep vein thrombosis (the CaVenT study): a randomised controlled trial. Lancet 2012;379:31-8.

9. Haig Y, Enden T, Grøtta O, Kløw NE, Slagsvold CE, Ghanima W, et al. Post-thrombotic syndrome after catheterdirected thrombolysis for deep vein thrombosis $(\mathrm{CaVenT})$ : 5-year follow-up results of an open-label, randomised controlled trial. Lancet Haematol 2016;3:e64-71.

10. Comerota AJ, Kearon C, Gu CS, Julian JA, Goldhaber SZ, Kahn SR, et al. Endovascular Thrombus Removal for Acute Iliofemoral Deep Vein Thrombosis. Circulation 2019;139:1162-73.

11. Notten P, Ten Cate-Hoek AJ, Arnoldussen CWKP, Strijkers RHW, de Smet AAEA, Tick LW, et al. Ultrasound-accelerated catheter-directed thrombolysis versus anticoagulation for the prevention of post-thrombotic syndrome (CAVA): a single-blind, multicentre, randomised trial. Lancet Haematol 2020;7:e40-e9.

12. Bozkur K. Periferik Arter ve Ven Hastalıkları-Ulusal Tedavi Kilavuzu. In: Bozkurt AK, editör. Venöz Tromboemboli Tedavisi. 1. Baskı. İstanbul: Bayçınar Tıbbi Yayıncılık; 2016. s. 123-41.
13. Han H, Yang L, Liu R, Liu F, Wu KL, Li J, et al. Prominent changes in blood coagulation of patients with SARS-CoV-2 infection. Clin Chem Lab Med. 2020. pii: /j/cclm.ahead-of-print/cclm-2020-0188/cclm-20200188.xml.

14. Winokur RS, Sista AK. DVT Intervention in the PostATTRACT Era. Curr Treat Options Cardiovasc Med 2018;20:70.

15. Matusov Y, Weinberg AS, Liang R, Meza J, Friedman O, Tapson VF. Use of the Bedside-Placed Angel Catheter IVC Filter for Venous Thromboembolic Disease in Critically Ill Medical Patients. J Intensive Care Med 2020;35:225-32.

16. National Institute for Health and Care Excellence Venous Thromboembolism in over 16s; reducing the risk of hospitalacquired deep vein thrombosis or pulmonary embolism. NICE guideline [NG89] . London: NICE, 2018. Available at: www.nice.org.uk/guidance/ng89 [Accessed: December 14, 2018].

17. Zhou F, Yu T, Du R, Fan G, Liu Y, Liu Z, et al. Clinical course and risk factors for mortality of adult inpatients with COVID-19 in Wuhan, China: a retrospective cohort study. Lancet 2020;395:1054-62.

18. Chan JF, Yao Y, Yeung ML, Deng W, Bao L, Jia L, et al. Treatment With Lopinavir/Ritonavir or Interferon$\beta 1 \mathrm{~b}$ Improves Outcome of MERS-CoV Infection in a Nonhuman Primate Model of Common Marmoset. J Infect Dis 2015;212:1904-13.

19. Kim UJ, Won EJ, Kee SJ, Jung SI, Jang HC. Combination therapy with lopinavir/ritonavir, ribavirin and interferon- $\alpha$ for Middle East respiratory syndrome. Antivir Ther 2016;21:455-9.

20. Wang Y, Fan G, Salam A, Horby P, Hayden FG, Chen $\mathrm{C}$, et al. Comparative effectiveness of combined favipiravir and oseltamivir therapy versus oseltamivir monotherapy in critically ill patients with influenza virus infection. J Infect Dis 2019. pii: jiz656.

21. Gautret P, Lagier JC, Parola P, Hoang VT, Meddeb L, Mailhe M, et al. Hydroxychloroquine and azithromycin as a treatment of COVID-19: results of an open-label non-randomized clinical trial. Int J Antimicrob Agents 2020:105949.

22. Aktoz M, Altay H, Aslanger E, Atalar E, Aytekin V, Baykan AO, et al. Consensus Report from Turkish Society of Cardiology: COVID-19 and Cardiovascular Diseases. What cardiologists should know. (25th March 2020). Turk Kardiyol Dern Ars 2020;48:1-48. 